\title{
Brief Review of Options to Treat In-stent Restenosis of Femoro-popliteal
}

\section{Artery}

\author{
International Journal of Cardiology and Cardiovascular Disorder
}

Review Article

Usman Sarwar $\mathrm{MD}^{1 *}$, Muhammad Nadeem MD², Ali Hussain $\mathrm{MD}^{3}$, Nikky Bardia $\mathrm{MD}^{1}$ and Hassan Tahir $\mathrm{MD}^{4}$

${ }^{I}$ Department of Cardiology, University of South Alabama, Mobile, AL, USA

${ }^{2}$ Saint Micahel's Medical Center, NJ, USA

${ }^{3}$ Sentara Albemarle Medical Center, NC, USA

${ }^{4}$ Department of Cardiology, Heart Lung Vascular Institute, University of Tennessee Medical Center, Knoxville, TN, USA

\author{
*Correspondence author \\ Usman Sarwar MD \\ Department of Cardiology \\ University of South Alabama \\ Mobile \\ AL \\ USA \\ Submitted : 28 Sept 2021 ; Published : 12 Oct 2021
}

\begin{abstract}
Peripheral arterial disease (PAD) is affecting millions of people all around the world. The different kind of stents to treat PAD has been in use from last couple of decades. In-stent restenosis is common problem, faced by endovascular specialists that is still challenging to treat. In this article, we reviewed the different options available to treat in-stent restenosis of the femoral-popliteal artery.
\end{abstract}

Keywordls: Peripheral Artery in-stent Restenosis; Drug-eluting Stents; Drug-coated Balloon; Peripheral Artery Disease.

\section{Introduction}

As early as the 1960s, Charles Dotter introduced the idea of arterial remodeling by performing percutaneous therapy of femoropopliteal disease. Over two decades, there was a progressive development of angioplasty devices as well as strategies. Although these devices permitted the reconstruction of blood flow in stenotic arteries but the issues like vessel dissection and restenosis due to intimal hyperplasia remained torment to these interventions throughout follow-up. After these treatments, primary patency was substantially impacted by these factors and was significantly less than surgical revascularization options. To handle the acute issues of vessel recoil as well as flow-limiting dissection, operators began utilizing selfexpanding nitinol stents developed for the biliary tree in an off-label style with reasonably great results in the femoral and popliteal arteries [2]. In randomized control trials these devices demonstrated enhanced optimum walking distance and decreased restenosis after 1 year follow up. The development of drug-coated balloon (DCB) as a primary treatment for femoro-popliteal stenotic lesions without the use of long-term implants was a big advancement in the field of endovascular intervention. Studies that used Drug Coating Balloon (DCB) showed a remarkable vessel patency rate between $75 \%$ to $85 \%$. Additionally, lower bailout stent percentage of $3 \%$ to $7 \%$, recommending that these all-new drug-eluting modalities may delegate stents to a therapy algorithm of the past. Nonetheless, these randomized trials have concentrated on highly picked out lesions of lowered complexness, as well as several large registries demonstrated that with increase lesion complexity i.e., enhancing size and degree of calcification) stent placement still needed. Although DCBs and newer scaffold designs might minimize the complication of in-stent restenosis (ISR) moving on, interventionalists will still certainly continue to have a problem with this clinical conundrum $[1,3,4]$.

\section{Definition, Incidence and Classification}

In-stent restenosis (ISR) is defined as loss of luminal volume either from in growth of cells, extracellular matrix, or thrombus within the lumen of stented artery. Incidence of ISR within first year has been reported between $15--40 \%$ of patients in femoropopliteal area, rates are even higher after 1 year. A classification system for FP ISR was introduced by Tosaka in which ISR lesions are categorized into three distinct categories based on angiographic appearance Class I (focal ISR): lesions $<50 \mathrm{~mm}$ Class II (diffuse ISR) lesions $>50 \mathrm{~mm}$ whereas Class III represent ISR that is totally occluded $[5,6]$.

\section{Pathophysiology of In-Stent restenosis}

After balloon angioplasty or self-expandable stent deployment, the local vasculature reacts with an inflammatory reaction that triggers neointimal hyperplasia (NIH). Besides lesion, specific factors, such as smaller sized vessel diameter and longer lesions, patient characteristics, including diabetes mellitus as well as cigarette smoking history, can enhance the risk of ISR. Stent implantations is related to mechanical stress factors consisting of vessel prolongation, torsion, flexion, and expansion that further increase femoropopliteal in-stent restenosis (FP-ISR). Various other clinical and angiographic risk factors for bad outcomes are diabetes mellitus, lengthy lesions, existence, and persistent total blockage $[9,10]$. 
Options for Treating ISR

Brief review of different options available to treat FP-artery ISR are given below.

\section{Use of Drug Coated Balloon.}

Plain and cutting balloon angioplasty to treat FP artery ISR did not yield very successful result and had high target lesion revascularization (TLR) rate [24-26]. As compared to conventional balloon drug-coated balloon (DCB) has shown much better result. They are typical catheters with surface coated with a layer of the anti-proliferative drug. Randomized trials have shown that drug-coated balloon (DCB) is related to much less restenosis and TLR (Target Lesion Revascularization) than conventional balloon angioplasty (BA). The benefits of DCB to treat FP-ISR include inhibition of neointimal hyperplasia by delivering anti-proliferative drug and no addition of new metal and which has been shown in different trials (FAIR, PACUBA, DEBATE-ISR). The Femoral Artery In-Stent Restenosis trial
(FAIR) revealed that for FP artery-ISR, DCB was associated with much less recurrent restenosis and a greater outcome than conventional BA. Freedom from TLR was significantly greater in the DCB group than in the traditional (90.8\% vs. $52.6 \%$ at 12 months; $p<0.001$ ) [7]. The PACUBA trial, also showed that DCB is superior to BA with a much better vessel patency rate $(40.7 \%$ versus $13.4 \%)$. Another important trial (DEBATEISR) showed the use of DCB resulted in a considerable decrease in restenosis compared to traditional BA. At 1 year, the TLR was $13 \%$ in the DCB and $31 \%$ in the conventional BA, with 1 -year patency rate of $80.5 \%$ in DCB group. However, follow-up after 3 years shows that drug-coated balloon had a similar rate of restenosis as compared to conventional balloon angioplasty that suggested drug-coated balloon in associated with late catch phenomena. Currently different size and lengths of drug-coated balloons are available by different companies like Stellarex (Phillips), In. PACT (Med-tronic) and Ranger (Boston scientific) $[11,12,18]$.

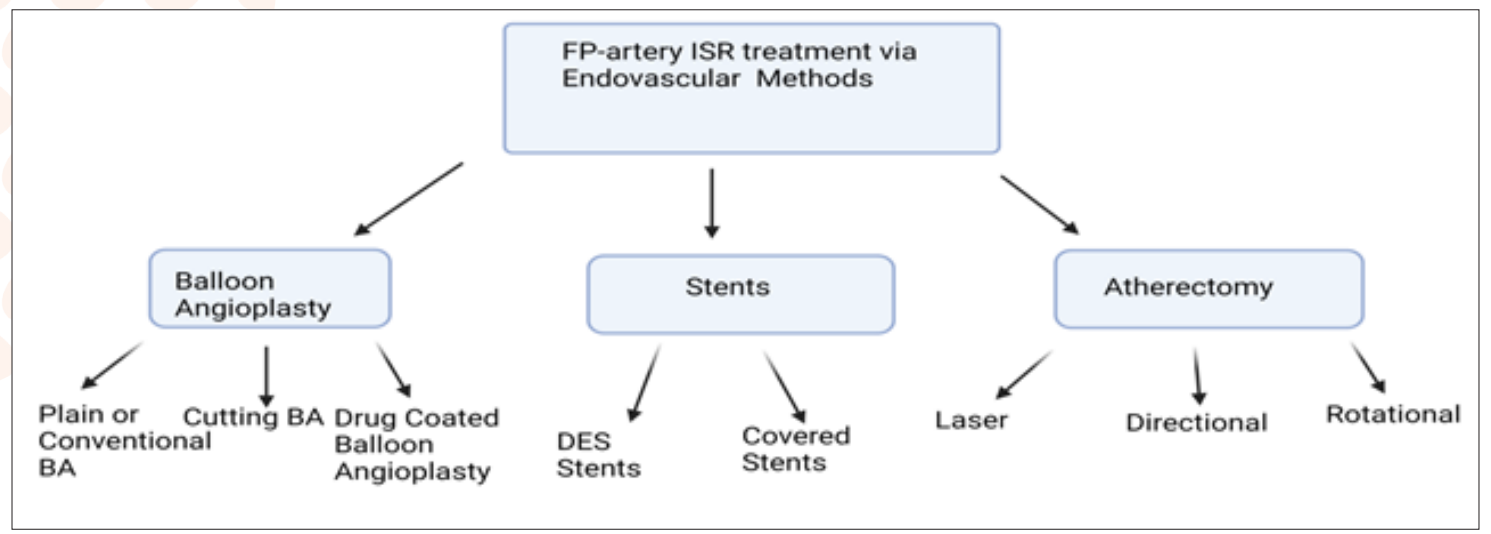

Figure : Illustration diagram showing treatment options for Femoro-popliteal in-stent restenosis.

(Created on biorender.com)

\section{Use of Stents}

Stent in stent techniques have also been evaluated to overcome the previously placed femoral artery in-stent restenosis problem. Drug eluting stent (DES), Covered stent and nitinol (self-expandable) are various kinds of available stent.

In Reline Trial VIABHAN stent graft versus angioplasty was compared as treatment option for femoral-popliteal in-stent restenosis. In this trial 39 patients were treated with VIABHAN endoprosthesis and 44 with plain balloon angioplasty. The end results showed freedom from TLR was much higher in VIABHAN group plus also better patency rate [19].

One of the important trials that evaluated drug-eluting stent to treat in-stent restenosis in femoral artery is Zilver-PTX. In this trial 108 patients with in-stent restenosis were treated with resolute drug-eluting stent. The mean lesion length was 133 mm. 31\% lesion has total occlusion. The result of this trial showed primary patency at 6 -month was $95 \%$ at that 12 -month was $78 \%$. Regarding target lesion revascularization, freedom from TLR $96.2 \%, 81 \%$ and $60.8 \%$ at 6 months, 1 year and 2 years respectively. This trial showed a stent fracture rate of $1.2 \%$ at 1 year [20].

\section{Catheter based atherectomy devices}

Atherectomy can debulk the plaque within the vessel wall which is a different approach as compared to use of stent and balloon that displaced the plaque against vessel walls. Different types of atherectomy methods are available to treat in-stent restenosis.

Laser atherectomy is one of those methods that proved to be useful. It used UV light to vaporize the intravascular material and useful in soft or moderate calcific plaques. Three diverse types of lasers are available including turbo elite, turbo power and turbo tandem. The efficacy of laser is evaluated in a couple of trials. The PATENT trial study was one of trials in which 99 patients with a target lesion length of $123 \mathrm{~mm} \pm 96 \mathrm{~mm}$ were treated with Turbo-Elite and Turbo-Booster laser and adjunctive balloon angioplasty was also done in $87 \%$ of cases. At 12 months evaluation showed vessel patency rate was close to $38 \%$ in general but class III lesions have patency rate of only $24 \%$. The EXCITE-ISR trial was one of the important trials using excimer laser as a treatment option. It is a randomized control trial comparing laser versus balloon angioplasty. The average length lesion was $19 \mathrm{~cm}$ with $20 \%$ of patients had lesion more than $30 \mathrm{~cm}$. Angioplasty was also used as adjuvant 
in laser group. The result of this trial showed that at 6 months showed with excimer laser plus PTA has higher freedom from target lesion revascularization (94.2\% vs. $79.2 \%)$ as compared to PTA alone group [21, 22].

Atherectomy via mechanical means also has been tried for ISR. There are 3 methods of mechanical atherectomy including directional atherectomy, orbital atherectomy, and rotational atherectomy. Directional atherectomy devices are Silver Hawk and Turbo Hawk. One single- center study using Silver Hawk for femoral-popliteal ISR showed TLR rate of $31 \%$ anterior rate of $24 \%$ after 1 year. This device is currently not FDA (Food and Drug Administration) approved. Jetstream (Boston scientific) atherectomy is an example of rotational atherectomy. One smaller study of 29 patients showed TLR rate of $14 \%$ at 6 -month and $41 \%$ at 12 -month with no new stent fractures. Vessel patency was $72 \%$ at 6 -month by ultrasound duplex. The jet stream should be avoided when an advanced stent fracture exists. Studies have also shown efficacy of the combined approach of atherectomy plus balloon angioplasty $[8,23,24]$.

\section{Conclusion}

The prevention as well as treatment of FP-ISR is an uphill battle in the endovascular field. Endovascular treatment for more complex FP-ISR remains to have high failure rates, although treatment options developing with time, they continue to be limited. Current trials results with available modern technologies have been heterogeneous regarding angiographic patterns including various other anatomic factors, contrast groups, and main endpoints, which makes an assessment of this clinical entity challenging, larger-scale randomized trials with follow-up are needed to additionally define the efficacy of all therapies.

\section{Conflicts of Interest \\ None}

\section{Funding}

None

\section{Acknowledgment}

None

\section{References}

1. Shammas NW (2013). An overview of optimal endovascular strategy in treating the femoropopliteal artery: Mechanical, biological, and procedural factors. Int J Angiol, 22(1), 1-8. [PMC free article] [PubMed] [Google Scholar]

2. Tosaka A, Soga Y, Iida O, et al (2012). Classification and clinical impact of restenosis after femoropopliteal stenting. J Am Coll Cardiol, 59(1), 16-23. [PubMed] [Google Scholar]

3. Payne MM (2001). Charles Theodore Dotter. The father of intervention. Tex Heart Inst J, 28(1), 28-38.

4. Maleckis K, Anttila E, Aylward P (2018). Nitinol Stents in the Femoropopliteal Artery: A Mechanical Perspective on
Material, Design, and Performance. Annals of Biomedical Engineering, 46(5), 684-704.

5. Gur I, Lee W, Akopian G, Rowe VL, Weaver FA, Katz SG (2011). Clinical outcomes and implications of failed infrainguinal endovascular stents. J Vasc Surg. 2011, 53(3), 658-666; discussion p. 667.

6. Tosaka A, Soga Y, Iida O, Ishihara T, Hirano K, Suzuki K, Yokoi H, Nanto S, Nobuyoshi M (2012). Classification and clinical impact of restenosis after femoropopliteal stenting. J Am Coll Cardiol, 59(1), 16-23. doi: 10.1016/j. jacc.2011.09.036. PMID: 22192663.

7. Mehran R, Dangas G, Abizaid AS, Mintz GS, Lansky AJ, Satler LF, Pichard AD, Kent KM, Stone GW, Leon MB (1999). Angiographic patterns of in-stent restenosis: Classification and implications for long-term outcome. Circulation, 100(18), 1872-8.

8. Zeller T, Dake MD, Tepe G, Brechtel K, Noory E, Beschorner U, Kultgen PL, Rastan A (2013). Treatment of femoropopliteal in-stent restenosis with paclitaxel-eluting stents. JACC Cardiovasc Interv, 6(3), 274-81.

9. Dake MD, Ansel GM, Jaff MR, et al (2011). Paclitaxeleluting stents show superiority to balloon angioplasty and bare metal stents in femoropopliteal disease: twelve-month Zilver PTX randomized study results. Circ Cardiovasc Interv, 4(5), 495-504. [PubMed] [Google Scholar]

10. Laird JR, Katzen BT, Scheinert D, et al (2010). Nitinol stent implantation versus balloon angioplasty for lesions in the superficial femoral artery and proximal popliteal artery: twelve-month results from the RESILIENT randomized trial. Circ Cardiovasc Interv, 3(3), 267-276. [PubMed] [Google Scholar]

11. Cassese, Salvatore, et al. "Drug-Coated Balloon Angioplasty for Femoropopliteal In-Stent Restenosis: The REPAIR Cooperation: A Meta-Analysis of Individual Participant Data From 3 Randomized Trials." Circulation: Cardiovascular Interventions, vol. 11, no. 12, Dec. 2018. DOI.org (Crossref), https://doi.org/10.1161/ CIRCINTERVENTIONS.118.007055.

12. Krankenberg H, Tübler T, Ingwersen M, et al (2015). Drugcoated balloon versus standard balloon for superficial femoral artery in-stent restenosis: The randomized Femoral Artery In-stent Restenosis (FAIR) trial. Circulation, 132(23), 2230-2236. [PubMed] [Google Scholar]

13. Kinstner CM, Lammer J, Willfort-Ehringer A, et al (2016). Paclitaxel-eluting balloon versus standard balloon angioplasty in in-stent restenosis of the superficial femoral and proximal popliteal artery: 1-year results of the PACUBA trial. JACC Cardiovasc Interv, 9(13), 13861392. [PubMed] [Google Scholar]

14. Stabile E, Virga V, Salemme L, et al (2012). Drug-eluting balloon for treatment of superficial femoral artery instent restenosis. J Am Coll Cardiol, 60(18), 1739-1742. [PubMed] [Google Scholar]

15. Virga V, Stabile E, Biamino G, et al (2014). Drug-eluting balloons for the treatment of the superficial femoral artery in-stent restenosis: 2-year follow-up. JACC Cardiovasc Interv, 7(4), 411-415. [PubMed] [Google Scholar] 
16. Liistro F, Angioli P, Porto I, et al (2014). Paclitaxel-eluting balloon vs. standard angioplasty to reduce recurrent restenosis in diabetic patients with in-stent restenosis of the superficial femoral and proximal popliteal arteries: the DEBATE-ISR study. $J$ Endovasc Ther, 21(1), 1-8. [PubMed] [Google Scholar]

17. Grotti S, Liistro F, Angioli P, et al (2016). Paclitaxel-eluting balloon vs standard angioplasty to reduce restenosis in diabetic patients with in-stent restenosis of the superficial femoral and proximal popliteal arteries: three-year results of the DEBATE-ISR study. J Endovasc Ther, 23(1), 5257. [PubMed] [Google Scholar]

18. Brodmann M, Keirse K, Scheinert D, et al (2017). Drugcoated balloon treatment for femoropopliteal artery disease: the IN. PACT global study de novo in-stent restenosis imaging cohort. JACC Cardiovasc Interv, 10(20), 2113-2123. [PubMed] [Google Scholar]

19. Bosiers M, Deloose K, Callaert J, Verbist J, Hendriks J, Lauwers P, Schroë H, Lansink W, Scheinert D, Schmidt A, Zeller T, Beschorner U, Noory E, Torsello G, Austermann M, Peeters P (2015). Superiority of stent-grafts for in-stent restenosis in the superficial femoral artery: twelve-month results from a multicenter randomized trial. $J$ Endovasc Ther, 22(1), 1-10. doi: 10.1177/1526602814564385. PMID: 25775672.

20. Zeller T, Dake MD, Tepe G, et al (2013). Treatment of femoropopliteal in-stent restenosis with paclitaxel-eluting stents. JACC Cardiovasc Interv, 6(3), 274-281. [PubMed] [Google Scholar]

21. Dippel EJ, Makam P, Kovach R, et al (2015). Randomized controlled study of excimer laser atherectomy for treatment of femoropopliteal in-stent restenosis: initial results from the EXCITE ISR trial (Excimer Laser Randomized Controlled Study for Treatment of FemoropopliTEal InStent Restenosis). JACC Cardiovasc Interv, 8(1 Pt A), 92-101. [PubMed] [Google Scholar]

22. Schmidt A, Zeller T, Sievert H, Krankenberg H, Torsello G, Stark MA, Scheinert D (2014). Photoablation using the turbo-booster and excimer laser for in-stent restenosis treatment: twelve-month results from the PATENT study. $J$ Endovasc Ther, 21(1), 52-60. doi: 10.1583/13-4538R.1. PMID: 24502484.

23. Shammas NW, Shammas GA, Banerjee S, et al (2016). JetStream rotational and aspiration atherectomy in treating in-stent restenosis of the femoropopliteal arteries: results of the JETSTREAM-ISR feasibility study. $J$ Endovasc Ther, 23(2), 339-346. [PubMed] [Google Scholar]

24. Dippel EJ, Makam P, Kovach R, George JC, Patlola R, Metzger DC, et al (2015). Randomized controlled study of excimer laser atherectomy for treatment of femoropopliteal in-stent restenosis: initial results from the EXCITE ISR trial (EXCImer Laser Randomized Controlled Study for Treatment of FemoropopliTEal In-Stent Restenosis). JACC Cardiovasc Interv, 8(1 PtA), 92-101. doi: 10.1016/j. jcin.2014.09.009. [PubMed] [CrossRef] [Google Scholar]

25. Krankenberg $H$, Tübler $T$, Ingwersen $M$, Schlüter $M$, Scheinert D, Blessing E, et al (2015). Drug-coated balloon versus standard balloon for superficial femoral artery in- stent restenosis: the randomized femoral artery in-stent restenosis (FAIR) trial. Circulation, 132(23), 22302236. doi: 10.1161/CIRCULATIONAHA.115.017364. [PubMed] [CrossRef] [Google Scholar]

26. Liistro F, Angioli P, Porto I, Ricci L, Ducci K, Grotti S, et al (2014). Paclitaxel-eluting balloon vs. standard angioplasty to reduce recurrent restenosis in diabetic patients with instent restenosis of the superficial femoral and proximal popliteal arteries: the DEBATE-ISR study. the DEBATEISR study. $J$ Endovasc Ther, 21(1), 1-8. doi: 10.1583/134420R.1. [PubMed] [CrossRef] [Google Scholar]
Copyright: (C2021 Usman Sarwar. This is an open-access article distributed under the terms of the Creative Commons Attribution License, which permits unrestricted use, distribution, and reproduction in anymedium, provided the original author and source are credited. 